\title{
Article \\ Fixed Effect Meta-Analytic Structural Equation Modeling (MASEM) Estimation Using Generalized Method of Moments (GMM)
}

\author{
Rahmawati Erma Standsyah (D), Bambang Widjanarko Otok * and Agus Suharsono
}

check for updates

Citation: Standsyah, R.E.; Otok, B.W.; Suharsono, A. Fixed Effect Meta-Analytic Structural Equation Modeling (MASEM) Estimation Using Generalized Method of Moments (GMM). Symmetry 2021, 13, 2273. https:// doi.org/10.3390/sym13122273

Academic Editors: Jinyu Li and Palle E.T. Jorgensen

Received: 18 September 2021 Accepted: 24 November 2021 Published: 29 November 2021

Publisher's Note: MDPI stays neutral with regard to jurisdictional claims in published maps and institutional affiliations.

Copyright: (c) 2021 by the authors. Licensee MDPI, Basel, Switzerland. This article is an open access article distributed under the terms and conditions of the Creative Commons Attribution (CC BY) license (https:// creativecommons.org/licenses/by/ $4.0 /)$.
Sepuluh Nopember Institute of Technology, Surabaya 60111, Indonesia; rahmawati.erma@unitomo.ac.id (R.E.S.); agus_s@statistika.its.ac.id (A.S.)

* Correspondence: bambang_wo@statistika.its.ac.id or dr.otok.bw@gmail.com

\begin{abstract}
The fixed effect meta-analytic structural equation modeling (MASEM) model assumes that the population effect is homogeneous across studies. It was first developed analytically using Generalized Least Squares (GLS) and computationally using Weighted Least Square (WLS) methods. The MASEM fixed effect was not estimated analytically using the estimation method based on moment. One of the classic estimation methods based on moment is the Generalized Method of Moments (GMM), whereas GMM can possibly estimate the data whose studies has parameter uncertainty problems, it also has a high accuracy on data heterogeneity. Therefore, this study estimates the fixed effect MASEM model using GMM. The symmetry of this research is based on the proof goodness of the estimator and the performance that it is analytical and numerical. The estimation results were proven to be the goodness of the estimator, unbiased and consistent. To show the performance of the obtained estimator, a comparison was carried out on the same data as the MASEM using GLS. The results show that the estimation of MASEM using GMM yields the SE value in each coefficient is smaller than the estimation of MASEM using GLS. Interactive GMM for the determination of the optimal weight on GMM in this study gave better results and therefore needs to be developed in order to obtain a Random Model MASEM estimator using GMM that is much more reliable and accurate in performance.
\end{abstract}

Keywords: GMM; fixed effect model; meta-analysis; MASEM

\section{Introduction}

Currently, there are many scientific studies whose discussions have the same topic but with various characteristics and results. Those studies are conducted from time to time and space to space on several global problems with the same goals. This condition demands researchers to review those scientific studies known as literature review. The main reason of this is to strengthen the overall conclusion from the findings in those studies [1]. Statistical methods that are capable of synthesizing studies, integrating studies, and gathering evidence of the studies, for the purpose of integrating findings of those studies, are called a meta-analysis [2]. A meta-analysis is defined as statistical analysis used to integrate a large collection of the analytical results from previous studies. One of the requirements needed in a meta-analysis is an assessment of the results of similar studies by finding the effect size value.

The effect size meta-analysis value consists of four types, namely effect size based on mean, proportion, odd ratio and correlation. The effect size based on correlation is obtained from the correlation of measured models such as Structural Equation Modeling (SEM). Currently, SEM is a widely used method in quantitative research. Many studies apply SEM model in various fields, for example in the fields of economic and social $[3,4]$, education and health [5,6], engineering [7,8], and many others. The previous studies using Structural Equation Modeling (SEM) technique were integrated with the meta-analysis 
based on the effect size correlation. The combination of SEM and meta-analysis technique is called Meta-Analytic Structural Equation Modeling (MASEM). MASEM has two steps of analysis, the first one is synthesizing the correlation or covariance matrix from several studies, and the second one is applying the SEM technique to explain the relationship between variables using combined correlation or covariance matrix [9].

MASEM is a correlated-based meta-analysis such that the type of MASEM data is a correlation matrix of the previous studies. Effect size correlation is divided into univariate and multivariate. Univariate effect size correlation is based on the bivariate correlation of two studies, and multivariate effect size correlation is based on the multivariate correlation of multiple studies. MASEM belongs to multivariate effect size correlation [10]. In general, according to the homogeneity of the MASEM models, as well as meta-analysis models, MASEM models are divided into fixed effect MASEM model and random effect MASEM model [11,12]. The difference between those two models is on the fixed effect model in an assumption that the population effect is homogeneous across studies such that the variance between studies component is ignored, and there is only variance within studies component in it. The random effect model is heterogeneous or there is variation on the effect of the studies population that involves both variance components between studies and within studies. In addition, the applied research of the MASEM method in Indonesia is similar to the state of health in East Java [13-15].

The fixed effect MASEM model was first developed analytically using Generalized Least Squares (GLS) method [16]. Further development was carried out computationally using Weighted Least Square (WLS) method or also known as Two Stage SEM (TSSEM) [17]. The development of the fixed effect MASEM model is limited, although there are many estimation methods that can be used to obtain more detailed study of the MASEM model. This is contrast to the development of the random effect MASEM model which has been widely studied, such as the DerSimonian and Laird's method [18], the moment method [19], maximum likelihood method [20], and etc.

In this study, the focus is on the fixed effect model MASEM as the first step in the further development of MASEM. The MASEM fixed effect was not estimated analytically using the estimation method based on moment. One of the classic estimation methods based on moment is the Generalized Method of Moments (GMM). GMM was first developed by Las Peter Hansen in 1982. GMM is an extension of the moment method. Basically, the GMM method compares the population moments with the sample moments then making it possible to estimate data studies having uncertainty problem parameter. GMM also has high level accuracy on data heterogeneity.

The MASEM model is sensitive to heterogeneity and the objective of MASEM is to obtain the homogeneity of the data. Based on the description above, fixed effect MASEM model needs to be developed analytically in order to obtain a good estimator and considering that MASEM is a method that has a problem with heterogeneity, and there is currently no study developing the fixed effect MASEM model using GMM estimation technique. Therefore, the researchers, in this study, propose a new method for estimating the fixed effect MASEM model using GMM, which is estimated analytically.

The symmetry of this research is based on the proof goodness of the estimator and the performance carried out by analytical and numerical. Estimation results for goodness of estimator proven by analytical were unbiased and consistent, while for estimator performance test, the estimation results were tested in sample question [16] and then compared with the performance of the estimation using GLS technique. The estimation results obtained are intended to be a new benchmark for the MASEM model, which has more reliable performance such that these results become a solution by integrating research with the same subject often found on social, economic, educational and other problems. 


\section{Literature Review}

This section describes the definition of the Fixed Effect Meta-Analysis Model, MetaAnalytic Structural Equation Modeling (MASEM) using Generalized Least Squares (GLS) Approach and Generalized Method of Moments (GMM).

\subsection{Fixed Effect Meta-Analysis Model}

The meta-analysis based on the homogeneity of the effect size model is divided into two types, namely fixed effect meta-analysis and random effect meta-analysis. The fixed effect meta-analysis assumes that the effect size value that is similar to or homogeneous among studies and the variance between studies is ignored in this model. There is only variance in within study. The random effect meta-analysis assumes that it is heterogeneous with there is variance between studies and within studies [11].

Fixed effect model is written as follows:

$$
y_{i}=\beta_{F}+e_{i}
$$

where

$y=$ studies effect size vector;

$\beta=$ combined effect size parameter;

$e=$ sampling error;

$i=1,2, \ldots, k$ studies unit;

$F=$ fixed effect case.

If $\boldsymbol{e}_{i}$ assumes normally distributed with mean 0 and variance $\sigma_{i}^{2}$. Weighted mean of effect size estimation $\bar{y}$ in the fixed effect model is [4]

$$
\bar{y}=\frac{\sum_{i=1}^{k} w_{i} y_{i}}{\sum_{i=1}^{k} w_{i}}
$$

where

$y_{i}=i$-th studies effect size;

$w_{i}=\frac{1}{\sigma_{i}^{2}}(i$-th studies weight);

$k=$ number of studies.

Sample variance $S_{F}^{2}$ with $w_{i}$ as weighting factor can be calculated using

$$
S_{F}^{2}=\frac{1}{\sum_{i=1}^{k} w_{i}}
$$

2.2. Meta-Analytic Structural Equation Modeling (MASEM) Using Generalized Least Squares (GLS) Approach

Becker's initial model in [16] is defined as regression model with $k$ a collection of correlation matrices and $p$ predictor variables. Thus, the multiple correlation is $p^{*}=\frac{p(p+1)}{2}$ will be estimated. This model is a multivariate meta-analysis model because the effect size value in MASEM is based on multivariate correlation. The meta-analysis model, namely Equation (1) is a univariate meta-analysis model and if the equation is applied to a 
multivariate model consisting of $k$ studies and $p^{*}$ correlations, then it can be written in the following form:

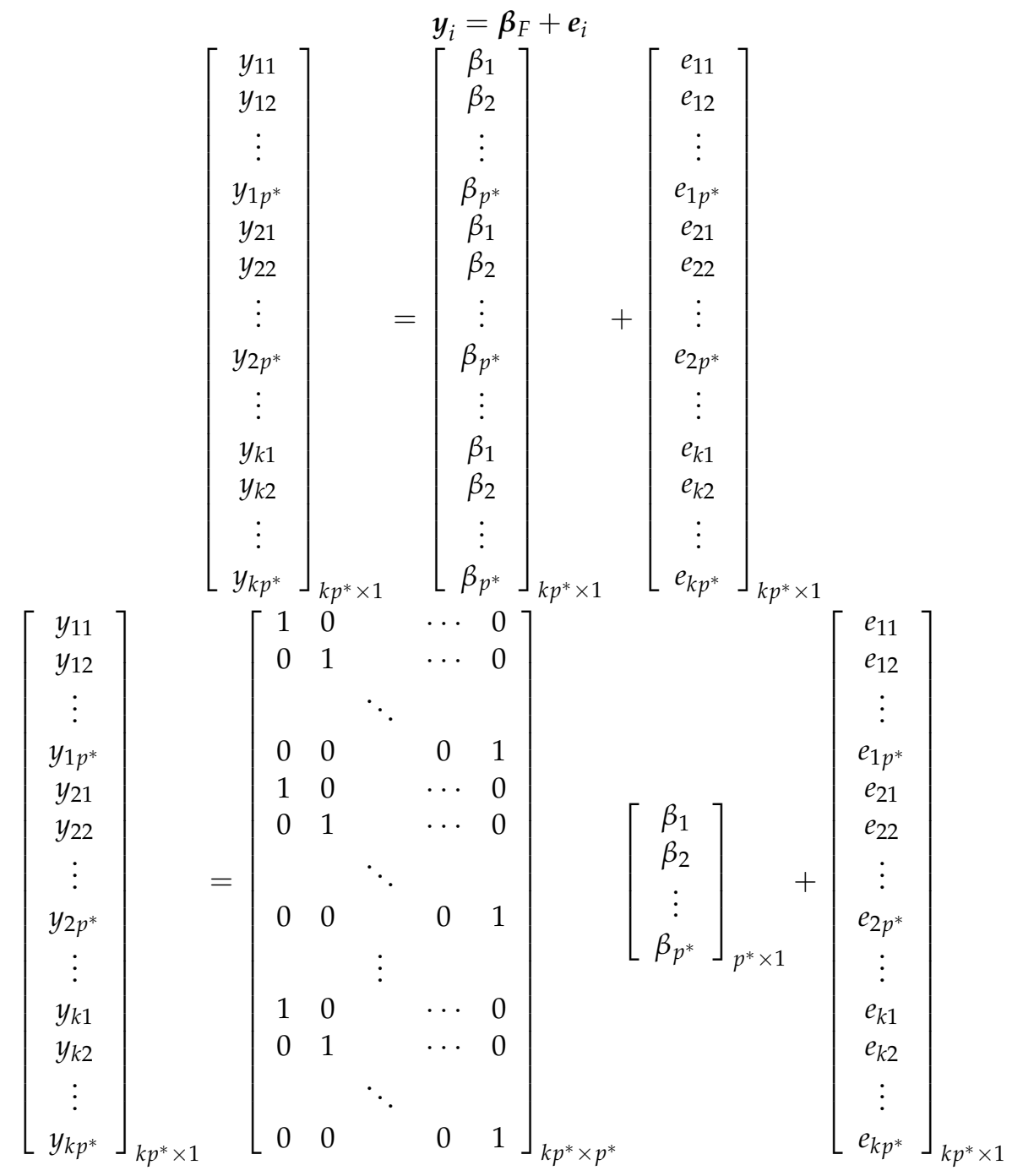

Then, the Becker model, in which $y$ equal $r$ and $\beta$ equal $\rho$, is:

$$
r=X \rho+e
$$

where

$r=$ correlation vector with $k p^{*} \times 1$ size;

$\boldsymbol{X}=$ identity matrix with $k p^{*} \times p^{*}$ size;

$\rho=$ combined correlation vector $p^{*} \times 1$ size;

$\boldsymbol{e}=$ error vector (unexplained Variance) $k p^{*} \times 1$ which is approximated by $\boldsymbol{\Sigma}$ variancecovariance matrix with $k p^{*} \times k p^{*}$ size.

If the GLS estimation steps have been carried out, it obtains

$$
\begin{gathered}
\hat{\rho}=\left(X^{\prime} \Sigma^{-1} X\right)^{-1} X^{\prime} \Sigma^{-1} \boldsymbol{r} \\
\operatorname{var}(\hat{\rho})=\left(X^{\prime} \Sigma^{-1} \boldsymbol{X}\right)^{-1}
\end{gathered}
$$

There are two models in the meta-analysis, which are fixed effect and random effect. In the two models, there are differences in the estimator value, which lies in the value of the variance-covariance matrices. Here is the difference between the two models: 
1. First effect model: Fixed effect meta-analysis model is $\boldsymbol{r}_{i}=\boldsymbol{\rho}+\boldsymbol{e}$ where $\boldsymbol{r} \sim N(0, \boldsymbol{\Sigma})$ then the correlation matrix estimator is

$$
\begin{gathered}
\hat{\rho}=\left(X^{\prime} \Sigma^{-1} X\right)^{-1} X^{\prime} \Sigma^{-1} r \\
\operatorname{var}(\hat{\rho})=\left(X^{\prime} \Sigma^{-1} X\right)^{-1}
\end{gathered}
$$

2. Random effect model: Random effect meta-analysis model is $\boldsymbol{r}_{i}=\boldsymbol{\rho}_{i}+\boldsymbol{e}$ and $\boldsymbol{\rho}_{i}=\boldsymbol{\rho}+u_{i}$ where $\boldsymbol{r} \sim N(0, \boldsymbol{\Sigma}+\boldsymbol{T})$ or equal to $r \sim N(0, \boldsymbol{\Psi})$ then the correlation matrix estimator is

$$
\begin{gathered}
\hat{\boldsymbol{\rho}}=\left(\boldsymbol{X}^{\prime} \boldsymbol{\Psi}^{-1} \boldsymbol{X}\right)^{-1} \boldsymbol{X}^{\prime} \boldsymbol{\Psi}^{-1} \boldsymbol{r} \\
\operatorname{var}(\hat{\boldsymbol{\rho}})=\left(\boldsymbol{X}^{\prime} \boldsymbol{\Psi}^{-1} \boldsymbol{X}\right)^{-1}
\end{gathered}
$$

\subsection{Generalized Method of Moments (GMM)}

There are many basic estimation methods, such as maximum likelihood estimation (MLE) and ordinary least square (OLS). In addition to the basic method there is also another basic estimation method which is Method of Moment (MM). MM can also be used as an alternative method which can be used to find a consistent estimator of a parameter. The basic pattern of this method of moment is to equate the population moments with the corresponding sample moments.

The weakness of MM can only be applied in the case where the number of moment conditions is equal to the number of estimated parameters, thus in 1982 The Generalized Method of Moments (GMM) was introduced. GMM is one of the methods to estimating parameters and an extension of Method of Moments (MM). The GMM estimator is used on parameters that are overidentified by moment conditions. If we have more moment conditions than the unknown parameters, it will result in overidentification estimates. However, GMM can be used when the number of moment conditions is not the same as the number of estimated parameters. This also allows GMM to work in cases of high heterogeneity of data. The definition of GMM based on [21] is supposed there is an observed sample $\left(x_{k}: k=1,2, \ldots, K\right)$ to estimate the $\boldsymbol{\theta}$ parameter which has size $t \times 1$ to the true value of $\boldsymbol{\theta}_{0}$. Supposed $E=\left[f\left(\boldsymbol{x}_{k}, \boldsymbol{\theta}_{0}\right)\right]=0$ is the set of $\boldsymbol{q}$ conditional moments and corresponding $f_{K}(\theta)$ sample moments. The criteria function is defined as follows:

$$
Q_{k}(\theta)=f_{K}(\theta)^{T} W f_{K}(\theta)
$$

where $W$ is a positive definite matrix, such that $\hat{\theta}=\operatorname{argmin}_{\theta} Q_{k}(\theta)$.

\section{Methodology}

This section describes the Meta-Analytic Structural Equation Modeling (MASEM) estimation method proposed using the method of Generalized Method of Moments (GMM).

\subsection{Parameter Estimation of Meta-Analytic Structural Equation Modeling (MASEM)}

The ordinary Structural Equation Modeling (SEM) model can be said to have $v$ number of exogenous latent variables and one endogenous latent variable. Based on that model, if there are $p$ number of indicators of exogeneous latent $v$ and endogenous latent $q$ indicators $\left(y_{1}, y_{2}, \ldots, y_{q}, x_{1}, x_{2}, \ldots, x_{p}\right)$, then there is $t=p+q$ random variable that can be written as $\left(a_{1}, a_{2}, \ldots, a_{t}\right)$ in each study having $n_{i}$ samples with total of $k$ study. The correlation among random variables of $a_{e}$ and $a_{s}$ where $a_{e}, a_{s} \in\left(a_{1}, a_{2}, \ldots, a_{t}\right)$ and $e \neq s$ is $c^{*}=\frac{t(t-1)}{2}$ in the $i$ study and is written as $\eta=\left[\eta_{i 12}, \eta_{i 13}, \ldots, \eta_{i 1 t}, \eta_{i 23}, \ldots, \eta_{i(t-1) t}\right]^{\prime}$ which $\eta$ is the sample correlation vector whereas the population correlation is written as $\gamma=\left[\gamma_{i 12}, \gamma_{i 13}, \ldots, \gamma_{i 1 t}, \gamma_{i 23}, \ldots, \gamma_{i(t-1) t}\right]^{\prime}$. 
In this study the researchers also use several assumptions including:

1. $\quad \boldsymbol{a}=\left[a_{1}, a_{2}, \ldots, a_{t}\right]^{\prime} \sim \mathrm{N}_{p}(\boldsymbol{\mu}, \boldsymbol{\Sigma})$;

2. asymptotic normal distribution $\sqrt{n_{i}}\left(\boldsymbol{\eta}_{i}-\gamma_{i}\right) \sim N(0, \Sigma)$

3. error vector $\zeta \sim N(0, \Sigma)$ such that the value of $\boldsymbol{\Sigma}_{i}$ according to [22] can be defined as follows:

$$
\operatorname{Var}\left(\eta_{i p q}\right)=\frac{\left(1-\gamma_{i p q}\right)^{2}}{n_{i}}
$$

and

$$
\begin{aligned}
\operatorname{Cov}\left(\eta_{i s t}, \eta_{i u v}\right)= & {\left[0.5 \gamma_{i s t} \gamma_{i u v}\left(\gamma_{i s u}^{2}+\gamma_{i s v}^{2}+\gamma_{i t u}^{2}+\gamma_{i t t}^{2}\right)+\gamma_{i s u} \gamma_{i t v}+\gamma_{i s v} \gamma_{i t u}\right.} \\
& \left.-\left(\gamma_{i s t} \gamma_{i s u} \gamma_{i s v}+\gamma_{i t s} \gamma_{i t u} \gamma_{i t v}+\gamma_{i u s} \gamma_{i u t} \gamma_{i u v}+\gamma_{i v s} \gamma_{i v t} \gamma_{i v u}\right)\right] / n_{i}
\end{aligned}
$$

\subsection{Fixed Effect Generalized Method of Moment (GMM) Estimation}

The fixed effect meta-analysis model assumes that the effect size value is similar for each study and variance between study component is ignored. To estimate the correlation vector in general with $c^{*}$ model length is as follows:

$$
\eta_{k c^{*} \times 1}=\Xi_{k c^{*} \times c^{*}} \gamma_{c^{*} \times 1}+\zeta_{k c^{*} \times 1}
$$

where

$\eta=$ correlation vector between indicators in each study with $k c^{*} \times 1$ size;

$\gamma=$ combined correlation vector with $c^{*} \times 1$ size;

$\Xi$ = matrix created by stacking $k$ identity matrix with $k c^{*} \times c^{*}$ size;

$\zeta=$ error vector (unexplained variance) with $k c^{*} \times 1$ size.

The steps for estimating the parameters from Equation (14) are as follows:

1. Determining the population moment condition [11]:

$$
f(\gamma)=\Xi^{\prime}(\eta-\Xi \gamma)
$$

2. Determining the sample moment condition:

$$
f_{K}(\gamma)=\frac{1}{k} \sum_{i=1}^{k}\left(\Xi_{\mathbf{i}}^{\prime}\left(\eta_{i}-\Xi_{\mathbf{i}} \gamma\right)\right)
$$

3. Constructing GMM function which is quadratic function of the sample moment:

$$
Q_{K}(\gamma)=f_{K}(\gamma)^{\prime} W f_{K}(\gamma)
$$

where $W$ is the weight estimator;

4. Minimizing function $Q_{K}(\gamma)$ :

$$
\begin{gathered}
\frac{\partial Q_{K}(\gamma)}{\partial \gamma}=0 \\
\frac{\partial f_{K}(\gamma)^{\prime} W f_{K}(\gamma)}{\partial \gamma}=0
\end{gathered}
$$

5. After substituting Equation (16) to Equation (19), we obtain the parameter estimation of GMM below:

$$
\begin{gathered}
\hat{\gamma}_{G M M}=\left(\Xi^{\prime} \Xi W \Xi^{\prime} \Xi\right)^{-1} \Xi^{\prime} \Xi \mathbf{W} \Xi^{\prime} \eta \\
\operatorname{var}\left(\hat{\gamma}_{G M M}\right)=\left(\Xi^{\prime} \Xi W \Xi^{\prime} \Xi\right)^{-1} \Xi^{\prime} \Xi \mathbf{W} \Xi^{\prime} \Sigma \Xi \mathbf{W} \Xi^{\prime} \Xi\left(\Xi^{\prime} \Xi W \Xi^{\prime} \Xi\right)^{-1}
\end{gathered}
$$

\subsubsection{The Unbiased Properties of the GMM Estimator}

One of the properties of a good estimator is unbiased, which means that the expected value of the estimator is the same as the value of the parameter or it can be written as 
$E\left(\hat{\gamma}_{G M M}\right)=\gamma$. The unbiased properties of the GMM estimator satisfies Lemma 1 which can be proved analytically by the proof found in Appendix A.

Lemma 1. If there is a Meta-Analytic Structural Equation Modeling (MASEM) model with a population correlation vector $\boldsymbol{\eta} \sim N_{p}(\boldsymbol{\mu}, \boldsymbol{\Sigma})$, a sample correlation vector $(\gamma)$ and an error vector $\zeta \xi \sim N(0, \Sigma)$ estimated by the generalized method of moment $(G M M)$, the value of $E\left(\hat{\gamma}_{G M M}\right)=\gamma$ is unbiased.

\subsubsection{The Consistent Properties of the GMM Estimator}

The properties of good estimator are not only unbiased but also consistent. The unbiased estimator $\hat{\gamma}_{G M M}$ is consistent if $\lim _{k \rightarrow \infty} Q_{K}\left(\hat{\gamma}_{k}\right)=0$ [23]. The consistent properties of the GMM estimator satisfies Lemma 2 in which the proof is shown in Appendix B.

Lemma 2. If there is a Meta-Analytic Structural Equation Modeling (MASEM) model with a population correlation vector $\eta \sim N_{p}(\boldsymbol{\mu}, \boldsymbol{\Sigma})$, a sample correlation vector $(\gamma)$ and an error vector $\zeta \sim N(0, \boldsymbol{\Sigma})$ estimated by the generalized method of moment $(G M M)$, the unbiased estimator $\hat{\gamma}_{G M M}$ is consistent that satisfies the value of $\lim _{k \rightarrow \infty} Q_{K}\left(\hat{\gamma}_{k}\right)=0$.

\subsubsection{Determination of $W$ Weight}

Parameter estimation using GMM involves weighting $\boldsymbol{W}$, which is a positive definite weight matrix, and the optimal value of $\boldsymbol{W}$ weight can produce the efficient estimator. The $W$ weight is defined as follows [24]:

$$
\lim _{k \rightarrow \infty} \operatorname{Var}\left(\sqrt{k} f_{K}(\gamma)\right)=W(\gamma)
$$

and

$$
\mathbf{W}_{\text {opt }}=[\boldsymbol{W}(\gamma)]^{-\mathbf{1}}
$$

The value of $\sqrt{k} f_{K}(\gamma)$ if approached by the Central Limit Theorem yields

$$
\sqrt{k} f_{K}(\gamma) \rightarrow N(0, S)
$$

where $S$ is the asymptotic moment variance of $\sqrt{k} f_{K}(\gamma)$. This implies that Equation (23) can also be written as

$$
W_{\text {opt }}=S^{-1}
$$

The $S$ matrix is defined as follows as:

$$
\begin{aligned}
\boldsymbol{S} & =\operatorname{Var}\left(\sqrt{k} \boldsymbol{f}_{K}(\gamma)\right) \\
& =k \operatorname{Var}\left(\frac{1}{k} \sum_{i=1}^{k}\left(\boldsymbol{\Xi}_{\mathrm{i}}^{\prime}\left(\boldsymbol{\eta}_{i}-\boldsymbol{\Xi}_{\mathrm{i}} \gamma\right)\right)\right) \\
& =\frac{1}{k} \sum_{i=1}^{k}\left[\boldsymbol{\Xi}_{\mathrm{i}}^{\prime}\left(\boldsymbol{\eta}_{i}-\boldsymbol{\Xi}_{\mathrm{i}} \gamma\right)\right]\left[\left(\boldsymbol{\eta}_{i}-\boldsymbol{\Xi}_{\mathrm{i} \gamma}\right)^{\prime} \boldsymbol{\Xi}_{i}\right] \\
& =\frac{1}{k} \sum_{i=1}^{k}\left[\boldsymbol{\Xi}_{i}^{\prime} \zeta_{i}\right]\left[\zeta_{i}^{\prime} \boldsymbol{\Xi}_{i}\right]
\end{aligned}
$$

Because the Equation (26) still contains $\gamma$ component, numerical iteration is carried out to find the solution. The numerical iteration steps are:

Step 1 Initialize $\boldsymbol{W}^{(i)}=\boldsymbol{I}$ which is substituted to Equation (20) such that the initial value of $\hat{\gamma}_{\mathrm{GMM}}^{(i)}$ is obtained.

Step 2 The estimated result of $\hat{\gamma}_{\mathrm{GMM}}^{(i)}$ is substituted to Equation (26) such that the value of $S^{(i)}$ is obtained.

Step 3 Update the weights by calculating $\boldsymbol{W}^{(i+1)}=\left(\boldsymbol{S}^{(i+1)}\right)^{-1}$. 
Step 4 Update the $\hat{\gamma}_{\mathrm{GMM}}^{(i+1)}$ value from Equation (20).

Step 5 Returns to step 2 and Calculate iteration until convergence.

\section{Results and Discussion}

In this section, the estimation results of Meta-Analytical Structural Equation Modeling (MASEM) using the Generalized Method of Moments (GMM) are tested on simulation data to show the performance of the GMM method and the results are compared to the GLS method.

\subsection{Results}

The estimation of Meta-Analytical Structural Equation Modeling (MASEM) with the GMM method was applied to the case real data in the article [15] with size of sample Table 1. It aims to show the performance of the estimator. The example case in this article concerns the correlation between 4 variables, poverty, economy, human resource (HR) and health variables. The coefficient $\beta_{1}$ shows the correlation between economy and poverty, The coefficient $\beta_{2}$ shows the correlation between health and poverty and the coefficient $\beta_{3}$ shows the correlation between HR and poverty. There are six studies as data sources for the application of the sample questions. They are as follows:

Table 1. Data of Sample for Implementation.

\begin{tabular}{ccc}
\hline No & Data of Sample & Size of Sample \\
\hline 1 & East Java & $n 1=38$ \\
2 & Central Java & $n 2=35$ \\
3 & Yogyakarta & $n 3=5$ \\
4 & West Java & $n 4=27$ \\
5 & DKI Jakarta & $n 5=6$ \\
6 & Banten & $n 6=8$ \\
\hline
\end{tabular}

There are six correlations from each data source (economy-poverty; health-poverty; HR-poverty; economy-health; economy-HR; health-HR) and arranged in $r_{36 \times 1}$ or $\eta_{36 \times 1}$ vector form,

$$
\begin{aligned}
& \boldsymbol{r}_{36 \times 1}=\left[\begin{array}{lllllll}
\boldsymbol{r}_{1_{6 \times 1}}^{T} & \boldsymbol{r}_{2_{6 \times 1}}^{T} & \boldsymbol{r}_{3_{6 \times 1}}^{T} & \boldsymbol{r}_{4_{6 \times 1}}^{T} & \boldsymbol{r}_{5_{6 \times 1}}^{T} & \boldsymbol{r}_{6_{6 \times 1}}^{T}
\end{array}\right]^{T} \text { Where } \\
& \boldsymbol{r}_{1_{6 \times 1}^{T}}^{T}=\left[\begin{array}{lllllll}
0.590 & -0.476 & -0.612 & -0.311 & -0.563 & 0.666
\end{array}\right]^{T} \\
& \boldsymbol{r}_{2_{6 \times 1}^{T}}^{T}=\left[\begin{array}{lllllll}
0.591 & -0.494 & 0.326 & -0.591 & 0.639 & -0.378
\end{array}\right]^{T} \\
& \boldsymbol{r}_{3_{6 \times 1}^{T}}^{T}=\left[\begin{array}{lllllll}
0.827 & -0.604 & -0.753 & -0.529 & -0.738 & 0.898
\end{array}\right]^{T} \\
& \boldsymbol{r}_{4_{6 \times 1}^{T}}^{T}=\left[\begin{array}{lllllll}
0.698 & -0.399 & -0.387 & -0.747 & -0.251 & 0.231
\end{array}\right]^{T} \\
& \boldsymbol{r}_{5_{6 \times 1}}^{T}=\left[\begin{array}{lllllll}
0.963 & -0.946 & -0.930 & -0.939 & -0.985 & 0.888
\end{array}\right]^{T} \\
& \boldsymbol{r}_{6_{6 \times 1}}^{T}=\left[\begin{array}{lllllll}
0.829 & -0.848 & -0.447 & -0.888 & -0.742 & 0.826
\end{array}\right]
\end{aligned}
$$

Or in GMM estimation

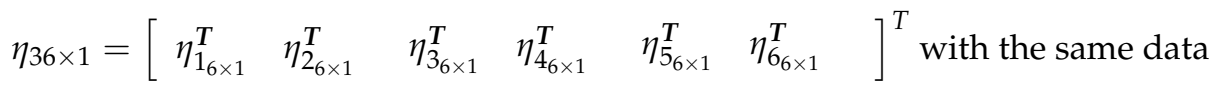

The estimated value obtained consists of a pooled correlation matrix ( $\hat{\rho}_{\mathrm{GLS}}$ or $\left.\hat{\gamma}_{\mathrm{GMM}}\right)$, the value of the coefficient between the latent variables and the fit of the model. The results of the GMM MASEM estimation are then compared to their performance with the results of the GLS MASEM estimator using initial weight $W^{0}=I$ presented in Table 2. 
Table 2. Result values.

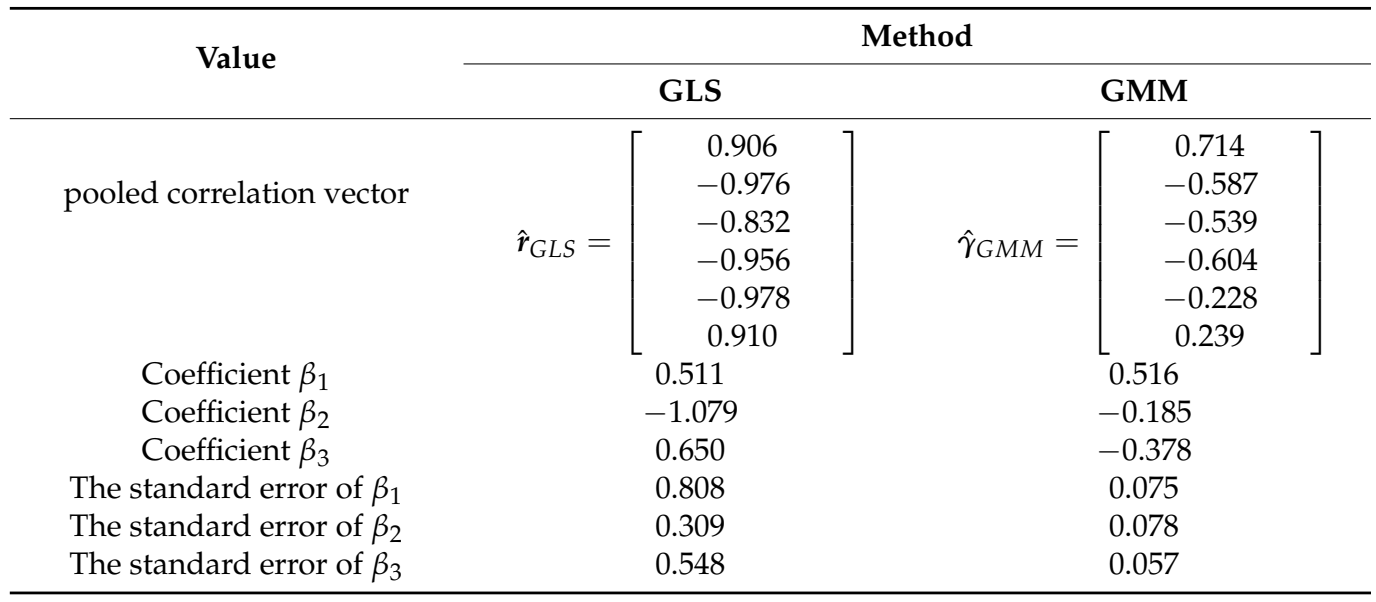

\subsection{Discussion}

The goodness of the estimator is unbiased and consistent. The MASEM estimator with GMM was proven to be unbiased and consistent; thus, it has the goodness of the estimator. To see the performance of the estimator, the estimation results of this study were compared with the estimations results of the MASEM GLS. The result of the model fit is the standard error of $\beta_{1}, \beta_{2}$ and $\beta_{3}$. This shows that the estimation using GMM produces the value better than the estimation using GLS because the $S E$ value of the GMM method in each coefficient is smaller than the GLS method. Thus, the GMM performance using the interactive GMM has better performance than the GLS method for the case of poverty in the island of Java.

\section{Conclusions}

The reliability of the performance of GMM depends on its weight, thus there are many ways that can be used to obtain the optimal weight. In this study, using interactive GMM which turned out to have a better performance then GLS result. Of course, future studies are also needed to determine a more optimal weight for the random model MASEM estimator using GMM that is much more reliable and accurate in performance.

Author Contributions: The authors' roles and contributions include: Conceptualization, B.W.O. and A.S.; Formal Analysis, R.E.S.; Methodology, B.W.O. and A.S.; Supervision, B.W.O. and A.S.; Validation, B.W.O. and A.S.; Visualization, R.E.S.; Writing-original draft, R.E.S.; Writing—review and editing, R.E.S., B.W.O. and A.S. All authors have read and agreed to the published version of the manuscript.

Funding: This research received funding support from the Ministry of Education, Culture, Research, and Technology of the Republic of Indonesia (Kemendikbud-Ristek) based on decree number: 8/E1/KPT/2021 in 2021 and Grand number 3/E1/KP.PTNBH/2021 in 2021.

Institutional Review Board Statement: Not applicable.

Informed Consent Statement: Not applicable.

Data Availability Statement: The data used to support the findings of this study are available from the research of the author before or the corresponding author upon request.

Acknowledgments: The authors wish to thank the Ministry of Education, Culture, Research and Technology of the Republic of Indonesia (Kemendikbud-Ristek) for the financial support provided to this research, the editorial team and the anonymous reviewers for their attention and helpful suggestions for the improvement and completion of this research.

Conflicts of Interest: The authors declare no conflict of interest. 


\section{Appendix A}

The steps to prove that $\hat{\gamma}_{\mathrm{GMM}}$ is an unbiased estimator is to simplify Equation (20) as follows as:

$$
\hat{\gamma}_{\mathrm{GMM}}=\boldsymbol{D} \eta
$$

where $D=\left(\Xi^{\prime} \Xi W \Xi^{\prime} \Xi\right)^{-1} \Xi^{\prime} \Xi W \Xi^{\prime}$, such that

$$
\begin{aligned}
E\left(\hat{\gamma}_{\mathrm{GMM}}\right) & =E(\boldsymbol{D} \boldsymbol{\eta}) \\
& =\boldsymbol{D} E(\boldsymbol{\Xi} \gamma+\boldsymbol{\zeta}) \text { as, } E(\gamma)=0 \\
& =\left(\boldsymbol{\Xi}^{\prime} \boldsymbol{\Xi} \boldsymbol{W} \boldsymbol{\Xi}^{\prime} \boldsymbol{\Xi}\right)^{-1} \boldsymbol{\Xi}^{\prime} \boldsymbol{\Xi} \boldsymbol{W} \boldsymbol{\Xi}^{\prime} \boldsymbol{\Xi} \mathrm{E}(\boldsymbol{\Xi} \gamma) \\
& =\left[\left(\boldsymbol{\Xi}^{\prime} \boldsymbol{\Xi} \boldsymbol{W} \boldsymbol{\Xi}^{\prime} \boldsymbol{\Xi}\right)^{-1} \boldsymbol{\Xi}^{\prime} \boldsymbol{\Xi} \boldsymbol{W} \boldsymbol{\Xi}^{\prime} \boldsymbol{\Xi}\right] \gamma \\
& =\gamma
\end{aligned}
$$

then, it is proven that $E\left(\hat{\gamma}_{\mathrm{GMM}}\right)=\gamma$ and has the unbiased properties of estimator.

\section{Appendix B}

The GMM estimator is obtained by minimizing Equation (17); thus, it will be proved that

$$
\begin{gathered}
\lim _{k \rightarrow \infty} Q_{K}\left(\hat{\gamma}_{k}\right)=0 \\
=\lim _{k \rightarrow \infty}\left(\frac{1}{k} \Xi^{\prime} \boldsymbol{\eta}-\frac{1}{k} \Xi^{\prime} \Xi \hat{\gamma}_{k}\right)^{\prime} W\left(\frac{1}{k} \Xi^{\prime} \boldsymbol{\eta}-\frac{1}{k} \Xi^{\prime} \Xi \hat{\gamma}_{k}\right)=0 \\
=\lim _{k \rightarrow \infty} \frac{1}{k^{2}}\left[\left(\boldsymbol{\Xi}^{\prime} \boldsymbol{\eta}-\boldsymbol{\Xi}^{\prime} \boldsymbol{\Xi} \hat{\gamma}_{k}\right)^{\prime} \boldsymbol{W}\left(\boldsymbol{\Xi}^{\prime} \boldsymbol{\eta}-\boldsymbol{\Xi}^{\prime} \boldsymbol{\Xi} \hat{\gamma}_{k}\right)\right]=0
\end{gathered}
$$

It is true that the unbiased estimator $\hat{\gamma}_{\mathrm{GMM}}$ is consistent with satisfies the value $\lim _{k \rightarrow \infty} Q_{K}\left(\hat{\gamma}_{k}\right)=0$.

\section{References}

1. Hartung, J.; Knapp, G.; Sinha, B.K. Statistical Meta-Analysis with Applications; John Wiley \& Sons, Inc.: New York, NY, USA, 2008; ISBN 3175723993

2. Glass, G. V Primary, Secondary and Meta-Analysis of Research. Am. Educ. Res. Assoc. 1976, 5, 3-8. [CrossRef]

3. Suyanto, S.; Purnomo, B.; Standsyah, R.E. Impact of Education and Health on the Unemployment Rate and Economy of East Java. Sinergi. J. Ilm. Ilmu Manaj. 2019, 9, 26-31. [CrossRef]

4. Zhao, W.; Kang, J.; Xu, H.; Zhang, Y. Relationship between contextual perceptions and soundscape evaluations based on the structural equation modelling approach. Sustain. Cities Soc. 2021, 74, 103192. [CrossRef]

5. Kang, H.; Ahn, J.W. Model Setting and Interpretation of Results in Research Using Structural Equation Modeling: A Checklist with Guiding Questions for Reporting. Asian Nurs. Res. Korean Soc. Nurs. Sci. 2021, 15, 157-162. [CrossRef] [PubMed]

6. Yin, H.; Huang, S. Applying structural equation modelling to research on teaching and teacher education: Looking back and forward. Teach. Teach. Educ. 2021, 107, 103438. [CrossRef]

7. Kursunoglu, N.; Onder, M. Application of structural equation modeling to evaluate coal and gas outbursts. Tunn. Undergr. Sp. Technol. 2019, 88, 63-72. [CrossRef]

8. Yudatama, U.; Hidayanto, A.N.; Nazief, B.A.A.; Phusavat, K. Data to model the effect of awareness on the success of IT Governance implementation: A partial least squares structural equation modeling approach (PLS-SEM). Data Br. 2019, 25, 104333. [CrossRef] [PubMed]

9. Viswesvaran, C.; Ones, D.S. Theory Testing: Combining Psychometric Meta-Analysis and Structural Equations Modeling. Pers. Psychol. 1995, 48, 865-885. [CrossRef]

10. Cheung, M.W.; Chan, W. Meta-Analytic Structural Equation Modeling: A Two-Stage Approach. Psychol. Methods 2005, 10, $40-64$. [CrossRef] [PubMed]

11. Borenstein, M.; Hedges, L.V.; Higgins, J.P.T;; Rothstein, H.R. Introduction to Meta-Analysis; John Wiley \& Sons, Ltd.: New York, NY, USA, 2009; ISBN 9780470057247.

12. Hedges, L.V.; Vevea, J.L. Fixed- and Random-Effects Models in Meta-Analysis. Psychol. Methods 1998, 3, 486-504. [CrossRef]

13. Tohari, A.; Otok, B.W. Meta Analytic Structural Equation Modeling (Masem) Pada Faktor-Faktor Yang Mempengaruhi Derajat Kesehatan Di Jawa Timur. Pros. Semin. Nas. Mat. 2014, 19, 35-50. 
14. Ngafiyah, A.N.; Otok, B.W. Meta-Analitycstructural Equation Modeling (Masem) Pada Faktor-Faktor Yang Mempengaruhi Kemiskinan Di Pulau Jawa. Pros. Semin. Mat. Pendidik. Mat. 2014, 1, 51-62.

15. Otok, B.W.; Standsyah, R.E.; Suharsono, A. Purhadi Development of model poverty in Java using Meta-Analysis Structural Equation Modeling (MASEM). AIP Conf. Proc. 2019, 2194, 20078.

16. Becker, B.J. Using Results From Replicated Studies to Estimate Linear Models. J. Educ. Stat. 1992, 17, 341-362, reprinted in J. Educ. Behav. Stat. 1995, 20, 100-102. [CrossRef]

17. Cheung, M.W.L. Meta-Analysis A Structural Equation Modeling Approach; John Wiley \& Sons, Inc.: New York, NY, USA, 2015; ISBN 9781119993438.

18. DerSimonian, R.; Laird, N. Meta-analysis in clinical trials. Control. Clin. Trials 1986, 7, 177-188. [CrossRef]

19. Chen, H.; Manning, A.K.; Dupuis, J. A Method of Moments Estimator for Random Effect Multivariate Meta-Analysis. Biometrics 2012, 68, 1278-1284. [CrossRef] [PubMed]

20. Oort, F.J.; Jak, S. Maximum likelihood estimation in meta-analytic structural equation modeling. Res. Synth. Methods 2016, 7, 156-167. [CrossRef] [PubMed]

21. Kuersteiner, G.M.; Matyas, L. Generalized Method of Moments Estimation; Cambridge University Press: Cambridge, UK, 1999; Volume 95, ISBN 9780521660136.

22. Hedges, L.V.; Olkin, I. Joint Distribution of Some Indices Based on Correlation Coefficients; Elsevier: Amsterdam, The Netherlands, 1983.

23. Ghazali, M. Regresi Data Longitudinal Dengan Estimasi Generalized Method of Moments Pada Pemodelan Penduduk Miskin di Indonesia Tahun 2008-2012. Doctoral Dissertation, Institut Teknologi Sepuluh Nopember, Surabaya, Indonesia, 2016.

24. Chausse, P. Computing Generalized Method of Moments and Generalized Empirical Likelihood with R. J. Stat. Softw. 2010, 34, 1-35. [CrossRef] 